\title{
GUSTAV MAHLER: ENTRE A GENIALIDADE E A OBSESSÃO
}

\section{Viviana Carola Velasco Martínez; Gustavo adolfo Ramos Mello Neto; Daniela Rosolen GALETTI DA SILVA}

\author{
Viviana Carola Velasco \\ Martínez \\ Universidade Estadual \\ de Maringá (UEM), \\ Professora do \\ Departamento de \\ Psicologia, Programa \\ de Pós-graduação em \\ Psicologia, \\ Maringá/PR, Brasil. \\ Gustavo Adolfo Ramos \\ Mello Neto \\ Universidade Estadual \\ de Maringá (UEM), \\ Professora do \\ Departamento de \\ Psicologia, Programa \\ de Pós-graduação em \\ Psicologia, \\ Maringá/PR, Brasil. \\ Daniela Rosolen \\ Galetti da Silva \\ Universidade Estadual \\ de Maringá (UEM), \\ Mestre pelo \\ Departamento de \\ Psicologia, Programa \\ de Pós-graduação em \\ Psicologia, \\ Maringá/PR, Brasil.
}

RESUMO: Este trabalho tem como objetivo fazer uma leitura psicanalítica de alguns aspectos da vida e obra de Gustav Mahler, de forma a propor uma relação entre a genialidade e a neurose obsessiva que acometia o músico, e sua particular relação com a morte. Em torno de algumas das suas obras, como o ciclo Kindertotenlieder, a 3 a Sinfonia e a 10a esta última inconclusa, tecemos principalmente a trama edípica em que a morte, fantasiada ou não, se apresenta como possível solução. Um destaque especial é dado ao célebre encontro do compositor com Freud e sua "única" sessão de análise.

Palavras-chave: neurose obsessiva; Gustav Mahler; psicanálise; genialidade, música.

Abstract: Gustav Mahler: Between genius and obsession. This paper aims to make a psychoanalytic reading of Gustav Mahler's life and work, in order to propose a relationship between genius and the obsessional neurosis that affected the musician, and his special relationship with death. Around some Mahler's works, as the cycle Kindertotenlieder, the 3rd and 10th Symphony these latter unfinished -, we wove primarily oedipal, complex in which death, costumed or not, is presented as a possible solution. Special emphasis is given to the famed meeting of the composer with Freud and his "unique" analysis session.

Keywords: obsessional neurosis; Gustav Mahler; psychoanalysis; genius; music.

DOI - http://dx.doi.org/10.1590/1809-44142017003010 


\section{INTRODUÇÃO}

Este artigo tem como objetivo analisar uma possível relação entre a genialidade e a neurose obsessiva. Escolhemos Gustav Mahler (1860-1911), o compositor, não só pelo seu célebre encontro com Freud, mas devido a um duplo interesse. De um lado, está a importância que a psicanálise dá à arte e às produções do espírito de maneira geral e, de outro, o fato de que este texto foi produzido como parte de um projeto de pesquisa maior, cujo objetivo era o de analisar e descrever o discurso psicanalítico sobre a neurose obsessiva depois de Freud. Isto é, uma historicização do pensamento psicanalítico, através do aporte a seus objetos. Afinal, foi com a neurose obsessiva, além da histeria, que Freud e Breuer fizeram nascer a psicanálise.

Para isso, recorremos a artigos indexados no Psyclnfo (APA) e aos publicados em diversas revistas especializadas1. Sobre o compositor, especificamente, consultamos vários livros, entre eles o de Alma, sua esposa.

Com esse material, entramos nos domínios da psicanálise extramuros e realizamos uma leitura-escuta flutuante dos textos e algo da música do compositor, buscando inspiração para seguir as possíveis manifestações do inconsciente nesse material que nos convida à interpretação. A música, afirma Federn (apud STEIN, 2007), para além de uma perspectiva estética e filosófica, reflete, simboliza e comunica aspectos da vida interior do seu compositor.

\section{GustaV MAHLER; ALGO DA VIDA E DA OBRA}

Mahler é considerado um dos maiores e mais talentosos regentes austríacos. Nascido em 7 de julho de 1860, na Boêmia, foi o segundo dos quatorze filhos do casal Marie Hermann e Bernhard Mahler.

Seu talento musical se revelou muito cedo e recebeu um grande incentivo de seus pais. No entanto, o relacionamento do casal era bastante conturbado, pois o pai era um homem rude e muito agressivo. "Meus pais", afirma Mahler, "se davam como o fogo e a água. Ele era um teimoso, ela a própria candura. Sem essa aliança, nem eu, nem minha Sinfonia no 3 existiríamos. Quando eu penso nisso, sempre experimento uma estranha sensação" (apud VIGNAL, 1994, p. 72).

Segundo Kennedy (1988), essa sinfonia - Wunderhorn (A Trompa Mágica, 1895-96) - é bastante polêmica; chegou até a ser considerada crime por um crítico vienense, que censurou Mahler dizendo que ele mereceria ser preso por executá-la. Mas o autor discorda e a considera um avanço na carreira de Mahler, resumindo-a como: "uma exultante celebração da vida, física e espiritual, sensual e instintiva" (p. 106). E cita o próprio Mahler, que diz: "Há passagens que parecem tão misteriosas, tão sobrenaturais, que dificilmente posso reconhecê-las como obra minha" (p. 106). Talvez porque, como o próprio compositor afirma, essa sinfonia se deva à aliança de seus pais. Entre teimosia e candura, água e fogo, nasce Mahler e, nessa luta de opostos, se situará como um terceiro espectador, procurando conciliar seus sentimentos ambivalentes. São esses os ingredientes "misteriosos", "sobrenaturais" de Mahler que, identificado com os pais, já mortos nessa época, ele mesmo dá à luz uma sinfonia. Não é ao acaso que, para Schönberg, essa sinfonia parecia "uma batalha entre o bem e o mal", (KENNEDY, 1988, p. 106).

Segundo Mooney (1968), aos onze anos, Mahler foi morar com a família dos futuros músicos Grünfeld, para poder aprofundar seus estudos. Contudo, além de ser maltratado, presenciou uma relação sexual muito violenta e agressiva entre um dos músicos e a criada. Mahler tentou ajudar a moça, acreditando-a vítima, mas foi repreendido por ambos os amantes (MOONEY, 1968), ocupando novamente o lugar de terceiro excluído. Possivelmente, ele não compreendera que, mesmo agressiva e violenta, tratava-se de uma cena de amor, uma mistura de fogo e água. O pai o leva de volta para casa.

Com quinze anos, continua o autor, Mahler foi estudar no Conservatório de Viena e aos vinte anos iniciou sua carreira de regente no teatro Hall, na Áustria, até ser empregado em outros teatros em Praga, Leipzig e Budapeste (COLLINS, 1982). Foi nesse período que Mahler compôs a Sinfonia no 1 (Titã, 1884-88), a Sinfonia no 2 (Ressurreição, 1888-94) e a Sinfonia no 3 (Wunderhorn, 1895-96), além das canções Lieder

\footnotetext{
1 Agradecemos a Alexander Stein, diretor do projeto The Mind and Music, em Nova lorque, que forneceu referências preciosas para o nosso trabalho.
} 
eines fahrenden Gesellen (Canções de um viajante errante, 1983-85) e Lieder und Gesänge aus der Jugendzeit (Canções de um tempo de juventude, 1880-90).

Finalmente, em 1897, Mahler conquista um dos cargos mais cobiçados de toda Europa, o de maestro titular da Ópera Imperial de Viena (COLLINS, 1982).

No entanto, apesar das suas conquistas, uma sensação de estranheza o acompanhava sempre. Assim definia sua situação: "Sou três vezes sem lar, como natural da Boêmia, na Áustria; como austríaco, na Alemanha; como judeu, no mundo inteiro. Em toda parte um intruso, em nenhum lugar bem-vindo" (KUEHN, 1966, p. 7). Não fará mal supor aqui que, além do crescente antisemitismo, também esteja se referindo, sem percebê-lo, ao terceiro excluído da relação dos pais, como todo filho - já o dissemos - mas também à experiência de ser o terceiro excluído da relação da mãe sempre com um novo bebê - e foram quatorze! Isso nos remete tanto ao complexo de Édipo, como à cena primária e também ao desamparo; e, no jogo entre esses três fantasmas, estaria a produção de angústia e um incansável trabalho de criação/sublimação.

Em 1901, Mahler conhece Alma, filha do famoso pintor E. Schindler. Linda e vinte anos mais jovem que ele, tornou-se sua esposa em seguida. Duas filhas nasceram. Marie, que levava o mesmo nome da mãe de Mahler, morreu aos cinco anos de idade, de difteria, deixando Mahler inconsolável; e Ana, que teve longa vida (COLLINS, 1982).

Logo após a morte dessa filha, Mahler recebeu o diagnótico de um problema cardíaco grave. 0 fantasma da morte, diz Feder (1978), que sempre esteve presente em sua vida e na sua obra, materializavase com a morte da criança e a sua própria, que podia chegar a qualquer momento. Em 1907, Mahler mudase para os Estados Unidos, para dirigir a Ópera Metropolitana e, depois, participa da Orquestra Filarmônica em Nova York (KENNEDY, 1988).

Nesse período, de 1901 até a sua morte, em 1911, Mahler compôs as sinfonias no 4 (1899-1901), oo 5 (1901-1902), no 6 (1903-1904), no 7 (1904-1905), no 8 (1906), no 9 (1909-1910) e no 10 (1910-1911) - esta última inconclusa - além de canções como o ciclo Kindertotenlieder (Canções para crianças mortas, 19011904) e Das Lied von der Erde (A canção da Terra, 1907-1909).

Por outro lado, o casamento não ia bem. Os ciúmes, o medo de ser abandonado e da morte assombravam Mahler. É seu sofrimento que o levará a Freud (MAHLER, 1988). Mais tarde, a sua saúde piorou. O compositor voltou à Viena, onde morreu em 18 de maio de 1911, aos 50 anos, de endocardite bacterial, a mesma doença que teria matado sua mãe, em 1889 (KUEHN, 1966).

\section{MAHLER E FREUD: O ENCONTRO}

Após a morte da filha, Alma, em depressão, foi se tratar numa clínica onde conheceu e logo se tornou amante do famoso arquiteto W. Gropius. Assim, justificavam-se os ciúmes de Mahler, sobretudo ao receber uma carta do amante de sua esposa, endereçada curiosamente a ele, o que fez Mahler imaginar que o amante estaria lhe escrevendo para pedir a mão de Alma em casamento (COLLINS, 1982). Alma, então, revela toda a situação a Mahler, que fica extremamente angustiado frente à possibilidade de perdê-la, mesmo ela tendo decidido não abandoná-lo (GIROUD, 1989). Foi nesse contexto que Mahler decidiu consultar-se com Freud, em 1910, e lhe enviou um telegrama solicitando um encontro. Entretanto, logo em seguida ao primeiro telegrama, Mahler lhe enviou outro cancelando o pedido, e esse fato se repetiu por três vezes. Nao é difícil notar na repetição uma característica da neurose obsessiva, principalmente em torno da dúvida ou folie de doute, aponta Jones (1981).

Finalmente, encontraram-se na cidade de Leiden - que significa em alemão dor ou sorfrimento, algo que Freud e Mahler conheciam bem, além da preocupação com a morte -, onde se reúnem, numa extraordinária sessão de análise, um médico e um paciente famosos (FEDER apud STEIN, 2007).

Giroud (1989) relata que Freud, ao longo de sua entrevista com Mahler, supõe ser Marie o nome de sua mãe, e pergunta ao músico por que se casou com uma mulher com outro nome. Surpreso, Mahler responde ser precisamente Marie o segundo nome de Alma. Freud, então, diz a autora, observou que a mãe de Mahler era enfermiça e aflita, e que eram essas características que ele desejaria reconhecer em Alma. Da mesma forma, para Freud, Alma buscara em Mahler seu próprio pai e foi justamente a diferença de idade que tanto preocupava Mahler - que a atraiu. E as palavras de Alma: "Ele (Freud) tinha razão. Quando ele me conheceu, desejava que eu fosse 'marcada pelo sofrimento', foram essas suas exatas palavras (...). Eu, 
Viviana Carola Velasco Martínez; Gustavo Adolfo Ramos Mello Neto; Daniela Rosolen Galetti da Silva

também, procurei realmente um homem baixo, atarracado, mas dotado de sabedoria e de um espírito superior, como conhecera e amara meu pai..." (apud GIROUD, 1989, p. 107).

Nessa sessão, Mahler também compreenderá por que suas composições mais elaboradas eram repentinamente invadidas por melodias vulgares. Jones (1981) se refere à lembrança de Mahler, ainda menino, de uma terrível briga entre o pai e a mãe, que o obrigara a sair de casa correndo. Na rua, nesse instante, ouviu uma melodia popular tocada por um realejo. "Desde esse momento, opinava Mahler, a nobre tragédia e a fácil diversão estariam inexoravelmente unidas na sua mente e qualquer um desses sentimentos atraía o outro" (p. 91-92). Temos aí novamente a cena primitiva e uma solução de compromisso que se materializa nas suas composições, melodias comuns ou inferiores invadindo os momentos nobres de criação.

Leonard Bernstein (apud FOGUEL, 2009, p. 167) menciona a essa dualidade:

Mahler estava dividido ao meio, com o curioso resultado que qualquer qualidade que seja perceptível e decifrável em sua música, a qualidade diametralmente oposta, também o é. [...] Mahler nisso era único: é tudo isso, grosseiro e feminino, sutil e barulhento, refinado e rude, objetivo e sentimental, impetuoso e tímido, grandioso e auto-aniquilador, confiante e inseguro, adjetivo, antônimo.

Se o processo criativo de Mahler está marcado por essa dualidade, não é dificil pensar que sua fonte de inspiração esteja em torno da repetição incansável, não apenas da cena dos pais brigando, mas também em torno da cena dos amantes se amando. Por outro lado, veremos mais adiante, a visão do realejo também estará associada à morte do irmão Ernst.

A compreensão de Mahler deixa Freud satisfeito, apesar de não ter conseguido esclarecer a fachada sintomática da neurose obsessiva do regente (KUEHN, 1966). Esse trabalho analítico, afirma Jones (1981), num tom um tanto idealizado, permitiu que Mahler recuperasse sua potência e o casamento fosse feliz. Mas tal final vai ser interrompido, nove meses mais tarde, com a morte do compositor.

\section{MAHLER, A MORTE E A NEUROSE OBSESSIVA}

Isidor, o primeiro irmão a nascer, e a morrer acidentalmente antes dos dois anos de idade, lançará uma sombra sobre a vida do compositor, que nasce poucos meses mais tarde, inaugurando uma sequência de mortes, entre os irmãos, sempre substituídas por novos nascimentos (FEDER, 1978).

Aos seis anos de idade, afirma Feder (1978), após a morte de mais dois pequenos irmãos - Karl e Rudolph -, Mahler compõe, a pedido da sua mãe, a sua primeira peça: Polca com uma marcha fúnebre introdutória (Polka mit inem Trauermarsch als Einleitung; paradeiro desconhecido).

Entre seus onze e treze anos de idade, perdeu mais três irmãos: Arnold, Friedrich e Alfred, ainda muito pequenos. Porém, a morte mais perturbadora, quando estava com quinze anos de idade, foi a do seu irmão Ernst, um ano mais novo e a quem Mahler dispensou cuidados extremos durante a doença, uma pericardite.

A morte dá uma trégua a Mahler e somente aos seus vinte e um anos cobra a vida do oitavo irmão, Konrad, com menos de três anos de idade. Mas, aos seus vinte e cinco anos de idade, ela se materializa no suicídio do irmão Otto, então com vinte e dois anos. Finalmente, aos 29 anos de idade, Mahler, então regente em Budapeste, perderá, com poucos meses de diferença, a mãe, a irmã Leopoldine e o pai, ficando responsável por duas irmãs e um irmão que sobreviverão ao compositor (FEDER, 1978; MOONEY, 1968; COLLINS, 1982).

Em fevereiro de 1901, a morte o ameaçará mais uma vez. Uma incontrolável hemorragia retal, decorrente de uma hemorróida antiga e grave, lhe dá certeza do seu próprio fim e o obriga a priorizar, como nunca, a sua saúde. Lamenta não ter morrido e fantasia uma frase para seu obituário, "Gustav Mahler finalmente conheceu o destino que seus muitos crimes mereciam" (FEDER, 1978, p. 130), o que é interpretado pelo autor como uma resignação prematura resultante da culpa que o atormentava.

Talvez seu desejo fosse mesmo morrer nesse mês de fevereiro, pois era o aniversário da morte do pai e do suicídio do irmão Otto. Também acabava de ser publicada uma composição da sua juventude As Klagende Lied (Canção do lamento), cujo tema é a morte de um irmão mais novo que proporciona uma cruel satisfação ao mais velho. Dois irmãos, diz a lenda que a inspira, procuram uma flor vermelha para entregá-la a uma bela rainha e ganhar a sua mão em casamento. $O$ irmão mais novo, bom e gentil, encontrou a flor 
antes do mais velho que, invejoso, o mata. Porém, logo é desvendado o crime, pois uma música delata o assassino.

É a música do fratricídio, afirma Feder (1981), que nos leva ao sofrimento de Mahler pela perda de dez irmãos, entre eles, Ernest, como vimos, mas também a uma ambivalência entre desejos fratricidas e culpa, que são precisamente os temas das suas composições (COLLINS, 1982; GARCIA, 2000).

Por outro lado, a certeza de que poderia morrer nessa ocasião leva-o a pensar numa saída, há muito conhecida na sua vida: um nascimento para substituir aos que morrem. Isso explicaria, diz Feder (1978), o fato de Mahler, um solteirão de 41 anos, ter decidido rapidamente se casar pouco tempo após ter conhecido Alma quem, como uma espécie de porta para a imortalidade, Ihe daria filhos.

Mas, para que nasça uma criança é preciso que outra morra no lugar de Mahler, que sobrevive. Assim, e numa identificação com os pais em constante luto, compõe o ciclo Kindertotenlieder (Canções para crianças mortas), também conhecido como as canções Rückert, por se tratar da musicalização dos poemas que Friedrich Rückert (1788-1866) compôs para seus dois filhos mortos. Mas, que morte se pranteia, se Mahler ainda não tem filhos? Kennedy (1988) associa ao fato de um dos filhos de Rückert ter se chamado Ernest, como o irmão morto de Mahler.

Somente em 1907, diz Feder (1978), Mahler perde sua filha e diz compreender a dor do poeta Rückert que o inspirou: "Coloco-me na situação de quem perdeu um filho. Quando de fato perdi a minha, jamais poderia compor estas canções" (MAHLER, 1988). Seja como for, estamos diante de perdas que inspiram a composição, reatualizadas na morte da filha, na descoberta da sua doença e sua própria morte.

Também a morte de uma criança por negligência materna o inspirará. A canção Das Irdische Leben ( $A$ vida terrena), conta a história de uma criança com fome, mas a mãe condiciona a alimentação a plantar, colher, debulhar e moer o trigo para fazer o pão, deixando-a morrer, o que Feder (1978) associa à morte de Isidor, o primeiro irmão a morrer acidentalmente (talvez por negligência?).

Negligência, perda, culpa e pesar é também o que encontramos nas Kindertotenlieder. Eis aí, novamente, a identificação com a mãe, no que diz respeito ao cuidado de uma criança, mas desta vez é Ernst, a quem Mahler dedicou, em vão, todos seus cuidados. O seu sofrimento, marcado pela ambivalência, Ihe diz, por um lado, que não fez o suficiente e, por outro, que quis deixá-lo morrer.

Haveria, pois, em torno do nascimento e da morte de Ernst, um terrível enigma. Por um lado, seu nascimento não se dá para substituir uma criança morta que, no caso, seria Mahler - como com Isidor - e aí está o triunfo de Mahler, na inversão da ordem das mortes familiares, onde sempre uma criança mais nova, substitui ao filho mais velho morto. Por outro lado, a morte de Ernst, desse ponto de vista, pode ser fantasiada como um sacrifício, precisamente para que Gustav, o compositor, pudesse viver; mas é preciso expiar a culpa que disso resulta. Não é por acaso que o tema do sacrifício será o principal da ópera Ernst Duque von Schwaben (inacabada e cujo paradeiro é desconhecido), que Mahler começou a compor justamente aos quinze anos, após a morte de Ernst. Uma carta dirigida a seu amigo Steiner nos fala dessa ópera, do irmão Ernst e do realejo, que acima relacionamos à cena primitiva.

Agora as figuras pálidas da minha vida passam diante de mim como sombras de uma felicidade perdida há muito tempo, e a canção de saudade soa novamente em meus ouvidos. E uma vez mais estamos perambulando juntos por este campo familiar, e ali vemos em pé o tocador de realejo, chapéu estendido, com as mãos descarnadas. Nos sons dissonantes do seu instrumento, ouço saudações de Ernst von Swaben. Ele próprio parece surgir, tentando me abraçar, e, quando eu olho para ele de perto, vejo que é o meu pobre irmão. Véus caem. Imagens e sons empalidecem. (DE LA GRANDE apud GARCIA, 2000, p. 104)

Ópera provavelmente inspirada no poema de Ludwig Uhland (1832/2014), trata do conflito do jovem Ernst com o padrasto, o imperador, que persegue impiedosamente seu amigo Werner. $O$ enredo culmina com a morte de Ernst e de todos os amigos, como sacrifício e lealdade a Werner.

Temos aí o resultado de uma condensação de Ernst von Swaben, Ernst, o irmão, e Ernst filho de Rückert - todos mortos - instalando em Mahler uma culpa angustiante, não apenas por ter desejado a morte, mas por não ter podido evitá-la, o que nos remete a profundos conflitos edípicos, precisamente reativados na adolescência. Mahler pode ter vivido outra relação triangular com esse irmão mais novo, não só pelo seu nascimento que o destrona, mas pelo simples fato de ter que dividir a atenção da mãe com ele, sobretudo, por ele estar doente. 
Um episódio da sua infância, relatado por De La Grange (apud STEINBERG, 1999) é eloquente. Durante seu primeiro ano de vida, Mahler não conseguia dormir e ambos os pais acalmaram-no, cantando uma canção. Dois anos mais tarde, após o nascimento de Ernst, ele mesmo cantou para si, no seu berço, as mesmas melodias, talvez para confirmar que não estava morto, apesar do nascimento de um novo irmão. A mãe, diz Steinberg (1999), foi substituída pela sua própria canção e, mais tarde, pelas suas composições.

Só restava, então, desejar fervorosamente a morte desse rival, o que, numa franca formação reativa, transformou-se em dedicados cuidados. Se Mahler realmente desejou a morte do irmão, isso pode ter sido tão aterrorizante que ele precisou buscar o perdão muitas vezes ao longo de sua vida... e obra. Ao reafirmar a idéia de redenção e paraíso, encontrou sossego, não só para sua culpa, mas também o fez, é de se supor, como forma de "ressuscitar" seu irmão, prometendo-lhe o paraíso, como sua própria redenção.

Contudo, esse sofrimento parece que não se restringe à morte desse irmão em si mesma, mas aí, nessa morte, parece haver algo terrível, pois condensa a morte de mais nove irmãos, e se estende ao pai, ou mesmo à mãe, num território edípico sombrio. Morte desejada, cultuada, musicalizada, celebrada e o sofrimento (e prazer) que daí advém ganha força, no futuro, quando morre sua filha Marie.

Temos aí uma forma sutil e elaborada de algo bem mais simples e bruto, que é a ambivalência do obsessivo, a que haviamos nos referido acima.

A ambivalência também aparece nas batalhas entre opostos narradas em diversas canções. Segundo Feder (1981), Mahler representou em sua obra um jogo complexo e condensado de idéias antagonicas, como, por exemplo, nascimento e morte, sono e despertar, separação e união, sempre de uma forma muito criativa.

Outras marcas da morte nessa duplicidade de sofrimento e prazer encontramos na canção Das Himmlische Leben (A Vida no Paraíso). Inspirada num poema popular alemão, narra o canto de uma criança morta, descrevendo o paraíso. Se considerarmos o pensamento cristão da morte - Mahler já havia se convertido ao catolicismo desde 1897 - e a possibilidade de ir para o paraíso, para os não pecadores, sem dúvida temos aí uma espécie de solução de compromisso. Por um lado, a morte não seria tão temida, por outro, o paraíso prometido seria a garantia de imortalidade. Leimbremos que, para o pensamento cristão, uma criança somente pode ir para o paraíso se estiver livre do pecado original, ou seja, do pecado da carne em que foi concebida. Isso nos leva de volta à cena primária... a cena de fecundação.

Essa solução de compromisso, a morte seguida da ressurreição, manifesta-se como uma anulação retroativa, onde se mata o outro e a si mesmo e, em seguida, desfaz-se essa ação devolvendo-lhes a vida no paraíso ou, pelo menos, prometendo fazê-lo.

A morte também é o tema da canção Ich bin der Welt abhanden gekommen (Afastei-me do mundo), onde Mahler fala de um mundo que o julga morto, mas ele não contesta. Pelo contrário, declara-se morto para a agitação deste mundo, mas vivo, sozinho, em seu paraiso com seu amor e sua canção (MAHLER, 1988).

Talvez, aqui, não se trate verdadeiramente do paraíso cristão, dessexualizado e recalcador, mas do paraíso perdido, o ventre materno, e do desejo mais íntimo de todo homem de retornar a ele, numa verdadeira cena incestuosa. Sedutor, o ventre de Maria, a mãe, gera vida e gera morte. É a ilha materna, de que nos fala Ramos (2012); chegaremos a ela mais adiante.

Ainda no território da neurose obsessiva, os temas religiosos se repetem. A agressão, pecado, culpa, expiação e perdão vêm do Dia da expiação, praticado pelos judeus. Já a idéia de ressurreição é, evidentemente, um elemento cristão. De toda maneira, tais fundamentos se sustentam em torno de um grave crime que deve ser expiado.

Numa das passagens da Sinfonia $n^{\circ} 1$, Titã, uma marcha fúnebre foi composta a partir de uma melodia infantil, baseada na gravura Os funerais do caçador. Nela, a cena retratada é um cortejo fúnebre formado exclusivamente por animais, que acompanham o caçador morto. Se pensarmos na equivalência entre crianças e animais - entre os ratos e as crianças, por exemplo - podemos supor que haveria também uma equivalência entre o caçador e a figura paterna, o que justificaria edipicamente a ambivalência e o secreto desejo pela morte do pai. Isso, vimos, é algo familiar para o obsessivo. Contudo, o nome da gravura, escolhida como inspiração por Mahler, também é conhecida como Frère Jacques ou Bruder Martin (VIGNAL, 1994), onde tanto a palavra frère, em francês, quanto Bruder, em alemão, significa irmão... Isso nos leva de volta para o tema do fratricídio: Isidor, Ernst, Otto, os outros? 
Essa atração/medo pela/da morte, as questões edípicas revividas por Mahler e Alma em seu casamento, a "loucura da dúvida" em torno da decisão de se encontrar com Freud, a culpa, além da repetição e o fervor religioso presentes em suas composições nos conduzem ao diagnóstico de Freud, ao terreno da neurose obsessiva e, evidentemente, à psicanálise. Uma psicanálise pós-freudiana que reintroduz o complexo de Édipo na explicação do quadro. Mas um Édipo atuado também pelos pais, em que o que era simplesmente objeto da pulsão genital infantil passa a ser também sujeito ${ }^{2}$.

Segundo Joel Dor (1991), a mãe do obsessivo seria aquela que necessita um a-mais, pois o pai não pode preenchê-la plenamente, algo ficou faltando. O filho, pois, surge como aquele que vai dar o que ficou faltando, por isso, a mãe devota-lhe tanto amor. Devoção que, por sua vez, reforça a crença de ocupar um lugar especial no desejo materno.

No caso do obsessivo, esses cuidados maternos introduzem algo de mortífero no desejo: o incesto e o parricídio, pois, para preencher o desejo materno, é preciso matar o pai e impedir que ele volte a viver. Ora, sabemos que, com Freud, o pai assassinado volta como totem, mas, para o obsessivo, esse pai que volta deve continuar morto.

Por outro lado, o obsessivo também necessita do pai para separar-se da mãe, função essa paterna que precisamente permitirá que o sujeito se torne desejante. Para o obsessivo, a mãe não permite essa separação completa, portanto não permite o acontecer total da função paterna. Nesse caso, o obsessivo necessita matar e manter morto o ser-suporte dessa função, o pai. Morto no imaginário, o pai não pode fazer-se plenamente no simbólico. No entanto, mesmo o obsessivo necessita do pai como garantia contra o incesto, necessita dele como autoridade, como proibição. O que ocorre, então, é algo surpreendente: o obsessivo busca fazer-se de morto diante de seu próprio desejo e, se não o fizer, é ele quem tem que morrer.

Leclaire (1972) discute três pontos centrais em torno do tema da morte, ao relatar um caso de neurose obsessiva, o caso Jérôme: desejo e temor pela morte; identificação com o morto; e representação simbólica da morte.

Jérôme sonhava com múmias que se liquefaziam e com túmulos sendo carregados. Falava sobre sua satisfação em observar a múmia em sua aparência humana e se impressionava com o que dizia respeito ao seu movimento, ou melhor, falta de movimento, uma vez que precisava ser carregada, o que representava a passividade. O paciente queixava-se de não ter futuro e dizia querer poder liquidar seu passado, trabalhando sem parar. Então, vivia esperando a morte, aliás, vivia como se já estivesse morto, porque a morte resolveria seus conflitos.

Para o autor, diferente da histérica que vive o dilema de ser homem ou mulher, o obsessivo se pergunta: Estou morto ou vivo? Isso, diz o autor, vai além de ser uma simples pergunta, representa um sintoma. Se o paciente se identifica com a múmia, é porque ele também quer se manter intacto, talvez eterno. Assim, a relação do obsessivo com a morte é bastante ambivalente: aproxima-se da morte, fazendose de morto, como um animal acuado, digamos, para ter certeza de que pode continuar a viver. Seria uma espécie de morto-vivo. Aliás, é essa a característica de uma múmia no fantasma, corrente: alguém que retornará do mundo dos mortos para a vida. Ao presentificar a morte em seu discurso, ele a torna mais familiar, na tentativa de aliviar o medo que sente diante da possibilidade que ela aconteça.

A vida e a obra de Mahler, vimos, são exemplares enquanto discurso sobre a morte. Também a necessidade premente de trabalhar é marcante. Como Jérôme, Mahler trabalhava muito, mesmo aos domingos, e se autointitulava “o compositor de verão", por trabalhar mesmo no período de férias, pois, caso não o fizesse, seria tomado por uma angústia muito grande. Assim diz Alma Mahler (1988, p. 35): “Não tinha sossego nunca, em lugar algum. Por toda a parte, atormentava-o o medo de desperdiçar tempo de trabalho. Perseguido, acossado por um caçador invisível - a morte -, foi assim que o conheci durante os dez anos em que pude conviver com ele". Desde muito cedo, continua Alma (1988), Mahler vivia como se sentisse que estava predestinado a morrer jovem e, por isso, não se dava ao luxo de viajar, de tirar férias; pelo contrário, trabalhou muito até a sua morte.

2 Evidentemente, essa é uma forma lacaniana de pensar. Podemos ver algo assim magnificamente exposto em $O$ mito individual do neurótico, de Lacan (2008), escrito em 1953. Trata-se de uma releitura de 0 homem dos ratos, de Freud (1918/1990), onde a fantasmática do pai do paciente ganha forte destaque. 
É que compor, inclusive nas férias, seria a solução encontrada para suportar em si desejos apavorantes, vimos. Além disso, uma vez terminado o trabalho, Mahler estaria pronto para morrer, como alguém que já deixou sua vida organizada, da mesma forma que pensava Jérôme.

Por outro lado, o trabalho excessivo de Mahler, como uma característica da neurose obsessiva, representa também uma repetição, uma espécie de defesa contra impulsos destrutivos e autodestrutivos, mortais. De tal maneira que, compor sem descanso, estaria em torno de uma fantasia de poder ter domínio sobre a morte tão temida, de torná-la familiar e, quem sabe, menos aterrorizante ou, ainda, gozar com ela. Vemos, nas suas composições, que é Mahler quem decide quando a morte é vencida e quando ela vence, como na Sinfonia $\mathrm{n}^{\circ} 2$, Resurreição. $\mathrm{E}$, mesmo vencido, morto para o mundo, ele ainda poderá ser perdoado e viver no paraíso.

Assim, nascimentos e mortes, perdas e lutos se entrelaçam à criatividade. Eles são a fonte de inspiração das composições que resultam de um trabalho intenso de sublimação, mas nunca suficiente para Mahler, o que o leva a trabalhar sem parar, a compor sem parar. São avanços e recuos angustiantes em torno da cena primitiva, onde Mahler parece fundir o casal de pais - como água e fogo -, a vida e a morte dos irmãos/filhos, a alegria e a tristeza. Não é por acaso que a dualidade, vimos, é a marca das suas composições.

Também, a possibilidade mais concreta da sua própria morte se refletia na ideia aterrorizante de compor a sua nona e décima sinfonias (KENNEDY, 1988). Isso ocorria devido ao fato de que outros compositores como Beethoven, Brückner e Schubert morreram após terminar justamente as suas nonas sinfonias. E de fato, essa foi a última sinfonia completa de Mahler, mas o medo de ter o mesmo destino desses outros compositores não o impediu de criá-la, pois a morte também o seduzia. O compositor Alban Berg comenta o primeiro movimento da Nona Sinfonia de Mahler como a morte em pessoa anunciada com toda força. Para Kennedy (1988), Mahler conseguiu estampar nesta obra todo o seu misticismo gerado em torno da possibilidade do que poderia acontecer-lhe ao terminá-la.

Quanto à Décima Sinfonia (1910), algo semelhante acontece; teme morrer antes mesmo de terminá-la, como acontecera a outros compositores. E, efetivamente, Mahler veio a falecer antes de terminá-la, como se se tratasse de um destino inexorável, destino que ele devia ajudar a compor. No terceiro movimento, intitulado Purgatório e identificado com Cristo, Mahler clama "Deus, por que me abandonaste?", o que expressa seus sentimentos de abandono e culpa (FEDER, 1978). É precisamente o momento em que Mahler exige que Alma escolha entre ele e o amante e, numa franca regressão, a figura central na vida mental de Mahler é novamente a sua mãe e seus deslocamentos. Totalmente dependente do amor para sobreviver, ocupa uma posição privilegiada como filho único, como grande regente e músico. Assim, continua o autor, se a figura do Purgatório, nesta sinfonia inconclusa, foi inspirada pelo Purgatório, da Divina Comédia de Dante, a morte seria uma preparação para o paraíso e para a reunião com Beatriz, a mãe eterna.

Um "Mártir!", relata Alma (1988, p. 35), era o que Mahler dizia querer ser quando criança. E, uma vez adulto, se perguntava: "Será que é preciso morrer primeiro, para que depois as pessoas nos deixem viver?" (p. 37). Ora, ser um mártir ou viver mesmo depois de morrer implica em não ser esquecido. Antes disso, mártir é aquele que sofre tormentos, que paga por algo com a própria morte. Se paga, é porque deve. Um mau desejo já se torna um ato condenável, mesmo que não tenha sido efetivado na realidade material e, talvez, Mahler sentisse que precisava pagar por esses desejos. Um mártir, como Cristo, pois realiza um sacrifício de si mesmo, para a redenção dos homens, o que só pode significar um crime de sangue, o homicídio do pai (FREUD, 1915/1990).

Além disso, morto, supõe encontrar a redenção do paraíso e ver-se livre de uma culpa, uma dívida que passou a vida toda tentando pagar através de suas composições. Mahler não conseguiu evitar sua morte real, mas, através de seu trabalho, ele ainda tornou-se imortal.

\section{MAHLER, A MÚSICA E A MORTE: CONCLUSÕES}

Aqui chegados, podemos dizer que o inconsciente deixou-se aí revelar porque a música apareceu para Mahler como uma solução para a constante luta entre suas pulsões e o meio externo. No entanto, essa solução não é definitiva. Se sua criação se sustenta por sublimações, podemos pensar, contudo, que esse mecanismo sempre falha no obsessivo, porque a demanda pulsional é intensa; e assim podemos explicar a necessidade constante de Mahler de compor, de trabalhar obsessivamente. Sua música e sua criação 
estariam associadas inevitavelmente ao movimento pulsional, como uma espécie de sintoma com vistas à minoração da angustia. Mas não é só isso, pois, comparável ao sintoma, a obra de arte é solução de compromisso. Dessa forma, haveria uma relação intensa, sofrida e sintomática entre a genialidade e a neurose obsessiva.

Digamos que a pulsão não sublimada, ainda em estado bruto, se apossa dos resultados já sublimados e busca a satisfação através deles. Aliás, isso é comum em todas as neuroses: o recalcado, ou melhor, o defendido, se apropria do sublimado e o sexual encontra neste um escape inusitado.

Sabemos que foi Freud quem primeiro chamou a atenção para uma neurose obsessiva em Mahler, logo após encontrá-lo em Leiden. Podemos pensar que isso se consolida em torno da questão edípica, revivida em diferentes momentos da vida de Mahler. O nascimento de outros irmãos, entre eles Ernest; o sentimento de rejeição, como o de um terceiro na relação entre o pai e a mãe; isto é, triângulos de exclusão e sofrimento que se expressam bem na descrição que Mahler faz de si mesmo: como três vezes apátrida, como um estranho no mundo. Além disso, temos a relação entre Mahler e sua esposa que, como uma relação duplamente edípica, junta e envolve a mãe de Mahler e o pai de Alma. É claro que se trata aí de pai e mãe fantasmáticos.

Além disso, o tema da morte é constante na vida e na obra de Mahler, coisa que vimos ser característica nos obsessivos. Desde muito cedo, queixava-se da vida e da solidão - é de se pensar que o isolamento tenha aí um papel. Mais tarde, a morte se tornou tema recorrente em suas músicas, antes mesmo de perder sua filha e de descobrir que sofria de uma grave doença cardíaca. Nas fantasias de morte, ora esta era combatida e vencida, ora ela tornava-se vencedora. Para além disso, há ainda, em sua obra, fantasias com a redenção dos pecados e a recompensa com o paraíso. Mahler, também dissemos, sentia-se atraído por essas idéias, talvez porque esperasse com sua morte alcançar o perdão e o paraíso. Mas o paraíso é a mãe (admitamos que seja), a terceira mulher, de que fala Freud (1913/1990), a morte e o além da morte, isto é, a representação do incesto, da não separação. Portanto, tem-se, num só movimento, o pecado e a absolvição, mas esta última leva de volta ao pecado, o paraíso incestuoso, e isso forma um ciclo sem fim, de pecado-absolvição-pecado. É a ilha materna, a que Ramos (2012) se refere, como metáfora da busca incessante do obsessivo por um isolamento psíquico com a mãe e em torno da figura do pai ora morto, ora ressuscitado. O sintoma obsessivo seria precisamente uma resposta à intensa sedução da mãe, que convocaria o filho a suprir sua insatisfação. Vejamos, nas palavras do próprio autor:

Há na neurose obsessiva um núcleo de loucura muito proeminente. Loucura aqui tem o sentido de falsificação violenta da realidade, de tentativa de tradução violenta, como uma identificação projetiva, que busca pôr sentido onde não há, pois ali não houve metabolização. Esse núcleo diz respeito a uma crença ou a um conjunto de crenças autorreferentes, que giram em torno da ideia de grandeza do eu. Boa parte das defesas, sobretudo aquelas que têm o caráter de controle e onipotência, visa manter esse núcleo de crenças. E este último, por sua vez, parece surgir na relação com a mãe.

O obsessivo parece, então, ter criado uma "ilha", que ele "habita" e preserva. Essa "ilha" é, talvez, a "projeção", não no sentido psicanalítico tradicional, mas no imagético-geométrico (de imagem projetada no plano), da relação com sua mãe, em que ele "é" ao mesmo tempo um filho incestuoso (incestuoso inclusive no sentido de ter gerado a si próprio juntamente com a mãe) e uma criança magnífica. Trata-se, portanto, de algo ambivalente, fazendo conviver culpa e idealização.

A mãe que está aí pode ser uma mulher depressiva, como ocorre frequentemente e como aponta Kristeva (2002) e/ou histérica. Seja como for, trata-se de uma mulher de algum modo insatisfeita, ou ainda que não suporta viver com sua falta de satisfação... criança funciona aí como aquela a quem se encarrega de dissipar essa insatisfação. (RAMOS, 2012, p. 321-322)

Isso faria de Mahler um mártir, um Cristo que, em defesa da ilha materna, deve pagar pelo assassinato do pai, mas também um Caim, sempre ameaçado por Abel.

Por outro lado, a repetição de temas na obra de Mahler também nos faz pensar numa espécie de tentativa de dominar o excesso pulsional, ao estilo do fort da (FREUD 1920/1990). O mesmo podemos dizer do recurso às lendas, poemas e mitos do mundo judaico-cristão que teriam a finalidade de simbolizar musicalmente seu sofrimento psíquico e cultuá-lo, já que o obsesivo necessita desse culto. Mas a repetição 
e a tradução em palavras e em musicalizações da situação de desprazer servem como limite para a tensão gerada por ela, como observou Freud. No entanto, o alívio proporcionado por suas composições precisava ser sempre renovado, repetido, daí sua grande produção. Mas em compasso ao seu sofrimento, porque aí também encontrava uma fonte de prazer, como acabamos de dizer, pois se deseja a morte dos outros e, como pena, a própria morte também. É assim que o obsessivo precisará estar sempre em íntima relação com a morte para poder viver.

Ao final de contas, é seu luto interminável que o inspira (FEDER apud STEIN, 2007).

Recebido em: 10 de fevereiro de 2015. Aprovado em: 7 de agosto de 2015.

\section{REFERÊNCIAS}

COLLINS, D. Gustav Mahler's Summer of 1910. Bulletin of the Menninger Clinic, v. 46, n. 3, 1982, p. 255-279.

DOR, Joël. Estruturas e clínica psicanalítica. Rio de Janeiro: Taurus-Timbre, 1991.

FEDER S. Gustav Mahler, Dying. The International Review of Psycho-analysis, v. 5, 1978, p. 124-148. Gustav Mahler: the music of fratricide. The International Review of Psycho-analysis, v. 8 , 1981, p. 257-284.

FOGUEL, E. S. A banda de Mahler e o violino sinistro. Revista da Associação Psicanalítica de Porto Alegre, n. 37, jul./dez, 2009, p. 112-130.

FREUD, S. De guerra y muerte. Temas de actualidad (1915). Buenos Aires: Amorrortu, 1990. (Obras completas, 14). completas, 7)

De la historia de una neuroses infantil (1918). Buenos Aires: Amorrortu, 1990. (Obras 12). . El motivo de la elección del cofre (1913). Buenos Aires: Amorrortu, 1990. (Obras completas, 18).

. Más Allá del principio de placer (1920). Buenos Aires: Amorrortu, 1990. (Obras completas,

GARCIA, E. Gustav Mahler's choice. Psychoanalytic Study Child, n. 55, 2000, p. 87-110.

GIROUD, F. Alma Mahler ou a arte de ser amada. RJ: Rocco, 1989.

JONES, E. Vida y Obra de Sigmund Freud. Buenos Aires: Hormé, 1981.

KENNEDY, M. Mahler. RJ: Jorge Zahar Editor, 1988.

KUEHN, J. Encounter at Leyden: Gustav Mahler consults Sigmund Freud. Psychoanalytic Review, v. 52,1966, n. 4, p.5-25.

LECLAIRE, S. Jérôme o la muerte en la vida del obsesivo. Revista Uruguaya de Psicoanálisis, v. 13, n. 1,1972 , p. 91-117.

MAHLER, Alma. Minha vida. São Paulo: Martins Fontes, 1988.

MOONEY, W.E. Gustav Mahler: A Note on Life and Death in Music. Psychoanalytic Quarterly. 37, 1968, p. 88-102.

RAMOS, G. A. Obsessão e psicanálise depois de Freud. Campinas: Editora da UNICAMP, 2012.

STEIN, A. Gustav Mahler: A life in crisis. Stuart Feder. Psychoanalytic Review, v. 94, n. 3, 2007, p. 493498.

STEINBERG, S. Tragic absurdity in the music of Gustav Mahler. Psychoanalytic Review. v. 86, n. 6, dez, 1999, p. 853- 875 .

UHLAND, L. Über die Sage vom Herzog Ernst (1832). 2014. Disponível em: <http://gutenberg.spiegel.de/buch/-5085/1>. Acesso em: 17 jan. 2014.

VIGNAL, Marc. Mahler. São Paulo: Martins Fontes, 1994. 
Daniela Rosolen Galetti da Silva

danigaleti@hotmail.com

Gustavo Adolfo Ramos Mello Neto

garmneto@gmail.com

Viviana Carola Velasco Martínez

vcvmartinez@hotmail.com 